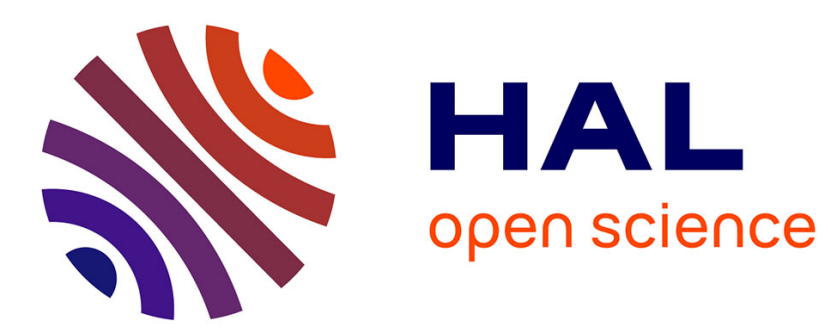

\title{
From policy making to service use. Down 's syndrome antenatal screening in England, France and the Netherlands
}

\author{
Carine Vassy, Sophia Rosman, Benedicte Rousseau
}

\section{- To cite this version:}

Carine Vassy, Sophia Rosman, Benedicte Rousseau. From policy making to service use. Down 's syndrome antenatal screening in England, France and the Netherlands. Social Science and Medicine, 2014, 106 (janvier), pp.67-74. hal-01493101

\section{HAL Id: hal-01493101 \\ https://hal.science/hal-01493101}

Submitted on 20 Mar 2017

HAL is a multi-disciplinary open access archive for the deposit and dissemination of scientific research documents, whether they are published or not. The documents may come from teaching and research institutions in France or abroad, or from public or private research centers.
L'archive ouverte pluridisciplinaire HAL, est destinée au dépôt et à la diffusion de documents scientifiques de niveau recherche, publiés ou non, émanant des établissements d'enseignement et de recherche français ou étrangers, des laboratoires publics ou privés. 
Title: From policy making to service use. Down 's syndrome antenatal screening in England, France and the Netherlands.

Authors: Carine Vassy ${ }^{1}$, Sophia Rosman ${ }^{2}$, Benedicte Rousseau ${ }^{3}$

Social Science and Medicine, 2014, 106, p.67-74

Abstract: In industrialised countries, certain biomedical innovations have come into general use, but the ways they are used vary considerably. Prenatal screening techniques for Down's syndrome are a perfect example of this. In 2010, screening rates stood at $61 \%$ in England and $84 \%$ in France; the previous year the rate was $26 \%$ in the Netherlands. The objective of our research, which took place in these three countries between 2008 and 2011, was to explain these differences. In these countries, public authorities focus on women's free access to innovations and on receiving their informed consent. But other aspects of screening policy vary, as do the health systems in which they are implemented. Our study shows that the sociotechnical settings which vary from country to country affected the interactions during the consultations we observed and thus impacted the decision of whether or not to screen.

Key words: policy, screening, France, England, Netherlands, Down's syndrome, informed consent

\footnotetext{
${ }^{1}$ Université Paris 13, Sorbonne Paris Cité, IRIS, EHESS, CNRS, UMR 8156, INSERM U997, 74 rue Marcel Cachin, F-93000 Bobigny, France

${ }^{2}$ Inserm U750-Cermes, Site CNRS, 7 rue Guy Môquet, F-94801 Villejuif Cedex, France

${ }^{3}$ Université Paris 13, Sorbonne Paris Cité, IRIS, EHESS, CNRS, UMR 8156, INSERM U997, 74 rue Marcel Cachin, F-93000 Bobigny, France
} 
Healthcare innovations are legitimised only when rules have been established to govern their use and when public authorities have created a regulatory framework (Baszanger et al, 2000). Such innovations raise specific issues where screening is concerned. They make it possible to calculate whether a given person runs a significant risk of developing a health problem, and then where necessary to offer diagnostic tests which are generally more expensive and/or dangerous. They are aimed at persons in good health, with a view to preventing problems for which they have no symptoms. When public authorities assess the benefits of screening to decide whether or not to introduce a policy which offers easier access to the service, they face a difficult choice because part of the population can demand access to these innovations as a right, whereas others will consider them to be an additional form of monitoring (Armstrong \& Eborall, 2012).

In Europe, programmes for prenatal screening for Down's Syndrome (DS) illustrate the dilemma facing public authorities. National policies have been developed only after considerable hesitation. In several European countries, a small number of obstetricians - who worked in university hospitals and who held positions in professional associations - were a driving force behind the introduction of innovations in prenatal diagnosis (foetal karyotyping following amniocentesis or trophoblast biopsy), and then screening (markers in the maternal blood and foetal ultrasound) (Reid, 1991). These obstetricians proposed experimental innovations to their patients, to allow them to see whether or not their foetuses had DS and thus to have an abortion should they so wish. Public authorities only intervened at a later date, in response to criticisms from obstetricians who highlighted their patients' requests for said innovations and demanded an end to the inequality of access to these tests. Public authorities 
feared that because it would lead to abortions, the generalisation of screening would be criticised by electors as a eugenistic approach (Petrogiannis et al., 2001; Vassy, 2006).

In the majority of European countries, public authorities opted for screening accessible to all and asked practitioners to obey two principles: that of informing all pregnant women of the existence of these tests, so as to counter inequalities of access, and that of providing said information without influencing their patients, leaving them free to choose whether or not to have the tests. The discourse on freedom of choice and neutrality is essential to the legitimisation of public policy. The notion of choice can be considered as an ideology which justifies the development of numerous healthcare policies (Alaszewski \& Brown, 2012).

This ideological framework for prenatal diagnosis and screening is criticised in social science works which believe freedom of choice and decision-making on the basis of objective and neutral information to be fiction. The fact that tests are proposed within a medical context gives immediate legitimacy to the objective of abortion (Green \& Statham, 1996). The unfavourable situation of disabled persons in western societies means that many women prefer to avoid their birth (Asch, 1999). Other women have no opinion on the matter and prefer to delegate this type of decision-making to professionals (Rapp, 2000). Under the guise of giving pregnant women greater choice and freedom, the State is introducing a new form of government in terms of controlling the quality of foetuses (Schwennesen et al, 2010).

Other social science researchers have conducted empirical studies of the gap between professional practices and the official discourse on informed consent.

In England, Th. Marteau and colleagues (1992) observed that practitioners present the tests during consultations in such a way as to encourage pregnant women to have them. They provided little information on the test, the disease that they were looking for or the 
significance of the future results. Presented as one of many other tests recommended for maternal and foetal health, prenatal screening thus becomes routine: women do not always understand that they must choose whether or not to accept it, nor that it can lead to a termination of pregnancy. In another study practitioners in England say that they are unable to be non-directive when they provide information on this screening (Williams et al., 2002). Other observations of consultations in England show that the information given to women is often very limited, and that the test is presented in a favourable light (Pilnick, 2008; Tsouroufli, 2011). The same observation is made in the USA (Press and Browner, 1997) and a study in France shows that practitioners do not always ask for consent for ultrasound screening (Champenois-Rousseau and Vassy, 2012). In other European countries, surveys confirm that certain pregnant women do not realise that they have a decision to make (Schwennesen et al. 2010; Favre et al., 2007).

Some of this research looks at how organisational factors affect interactions between pregnant women and healthcare professionals; for example, having all the tests in a single day in a onestop clinic in England (Tsouroufli, 2011), or the financial interests of the managers of a Health Maintenance Organization in the USA (Press and Browner, 1997). Yet we know little about the role of national screening policies. This topic is often neglected, even in studies on the decision-making processes of pregnant women with regard to prenatal screening in various countries (Crombag et al., 2013; Reid et al., 2009). Whilst in Europe these policies all have the same conceptual framework, in other aspects they are different; furthermore, they are implemented within specific healthcare systems, where standards governing pregnancy management existed before the introduction of this screening, were embedded in professional practices and could orient the implementation of public policies.

\section{Studying how public policy is implemented}


We propose to analyse the way screening consultations are organized and conducted as a means of implementing public policy within a health care system. We chose to not restrict ourselves to a study of the communication between healthcare workers and patients, but rather to analyse from policy making to service use and to draw attention to the organisational aspect so as to understand healthcare delivery (Griffiths, 2003).

Our international comparison bears upon both the characteristics of public policies and health systems, and upon the practices observed during consultations. We make the hypothesis that the former affect the latter, by creating specific sociotechnical settings. The concept of sociotechnical setting places the accent on the flexibility of the technical object, which may be used in different ways, depending on the network of actors in which it is embedded, whilst at the same time placing constraints on relations within said network (Akrich, 1992). Within these settings are embedded scripts, i.e. implicit expectations regarding the roles of users and care providers. We will show that settings vary and that they affect interactions between healthcare professionals and pregnant women.

The three countries compared are: England, where medical initiatives favouring the generalisation of screening must work alongside the institutions in charge of public health and which might be resistant to imperative screening (Faulkner, 2012); France, where innovations are driven by a relatively autonomous medical profession which must cope with a multitude of health organisations and a fragmented governance of the health system (Benamouzig, 2010) and the Netherlands, where medical initiatives have led to public controversy and to conflict with Parliament and the Government (Stemerding \& Van Berkel, 2001). The choice of these countries can also be justified by significant differences in screening uptake rates: $61 \%$ in England in 2010, 84\% in France in the same year, and 26\% in the Netherlands in 2009 (Blondel \& Kermarrec, 2011; Schielen, 2011; Ward, 2011a). 


\section{Method}

Our comparison relates to macro and microsocial qualitative data, which is a tried and tested methodology in sociology (Hantrais \& Mangen. 1996). In all three countries we analysed official documents from public authorities and professional healthcare associations, along with press articles and social science documents relating to prenatal policy. We also conducted fieldwork.

\section{English fieldwork:}

In February and March 2011, Bénédicte Rousseau and Carine Vassy working separately but in the same places, observed and recorded 16 consultations given by 6 midwives. These midwives were employed in the National Health Service (NHS) and worked at three consultation sites in socially mixed districts of an average-sized town in the East Midlands. The sociologists observed initial consultations with pregnant women with midwives presenting the first-trimester combined prenatal screening for DS. This combined test calculates a single estimation of risk, based on three variables (maternal age, serum markers and ultrasound measurement of the foetus's nuchal translucency).

In accordance with the recommendations of the NHS research ethics committee, who authorised this study, the sociologists prepared an information letter explaining their research, which was sent to pregnant women prior to their consultations. Just before the consultation, the sociologists asked whether the women agreed to the recording and to their being present, and received their written consent. There were a few refusals from the pregnant women, but the midwives agreed to the presence of the researchers. The consultations were then fully transcribed and anonymized.

\section{French fieldwork:}


Bénédicte Rousseau and Carine Vassy worked successively in a university hospital in the Paris region between October 2008 and December 2009 with the permission of the Head of the Obstetrics Department. The hospital is located in a working-class district and used by a relatively high population of immigrants. The sociologists observed consultations with women who were consulting for the first time and who were between their $11^{\text {th }}$ and $18^{\text {th }}$ weeks of amenorrhea. During the consultation, the women were offered a prenatal screening for DS through second-trimester serum-marker test. The sociologists asked the women in the waiting room if they agreed to the observation and recording of their consultation. Some women refused, but all healthcare professionals agreed to the sociologists being present. The researchers were thus able to fully observe, record and transcribe 34 consultations given by 6 midwives and 5 obstetricians.

\section{Dutch fieldwork:}

Sophia Rosman observed consultations in four private midwifery practices, located in two cities in the Netherlands between March and June 2009. She observed 25 initial consultations, given by 9 midwives. The first practice is located in a working-class district. The second practice is located in the same city, in a residential area. She also observed 5 midwives in another city who moved between one site located in a socially mixed district and a second site in a working-class district essentially inhabited by an immigrant population. The midwives saw the women as from their $7^{\text {th }}$ week of pregnancy and provided them with information on the combined prenatal screening test for DS. The sociologist obtained agreements from all midwives she asked to take part in the study. She either asked the pregnant women in the waiting room if she could attend their consultations and record them, or else the midwife introduced her to the women and requested their agreement. All women but one accepted. Twenty-two consultations were recorded and transcribed. 
We then conducted a qualitative, inductive and thematic analysis of the transcriptions of all the consultations, after they had been anonymized. We then coded the data using the following categories: the time devoted to the discussion about screening, the moment the information was delivered, the time allowed for the woman to make a decision, the use of documents on screening, the aspects of screening and diagnostic tests mentioned by the practitioner, any mention of the optional nature of screening by the practitioner, explicit recommendations in favor of screening by the practitioner, warnings about possible negative consequences of screening by practitioners, questions asked by pregnant women, uptake or refusal of screening by women. The results of this analysis were then linked to the data on screening policy in the 3 countries.

\section{Screening policy in England}

Serological markers for DS screening were invented in England in the 1980s. Due to the economic constraints of the NHS, obstetricians negotiated with local health authorities to set up more or fewer tests, depending on the budgets available, and perhaps reserving screening for older women because they run a greater risk of having a child with DS (Kerr, 2004). Following criticism regarding geographical variations in access to screening, in 2001 the Minister of Health announced that maternity departments must offer screening to all women, and tasked the National Screening Committee - a team from within the Department - with issuing recommendations for the techniques to be implemented (Kerr, 2004). This led to practices being standardized through the Down's Syndrome Screening Programme, set up and funded by the Department of Health in 2003. This programme is based on a network of local contacts, usually midwives, who encourage local actors to apply the good-practice recommendations, to have training and to coordinate with one another. 
The combined first-trimester screening is implemented since 2010 (NSC, 2008). If the test shows a risk of DS higher than 1/150, women are offered a diagnostic test - amniocentesis or trophoblast biopsy. Where a foetal anomaly is considered to be serious (such as DS), abortion is possible right up until the pregnancy comes to term. The National Institute for Clinical Excellence asks healthcare professionals to inform pregnant women about prenatal screening without influencing their choice (NICE, 2003).

Just like the rest of the pregnancy management, screening tests are free for pregnant women. They are proposed by the midwives who care for the women throughout their pregnancies. Midwives are NHS employees allocated to women in accordance with where they live. They meet pregnant women in a consultation centre in town and only send them to see a hospital obstetrician if there are complications. The midwife offers pregnant women the DS test during the first meeting, referring to the NHS brochure on prenatal screening sent by post prior to the consultation. If they are interested, the midwife makes an appointment at the hospital for the women to have the combined first-trimester test, which includes a blood sample to analyse serum markers and measurement of the foetus's nuchal translucency. This takes place during an ultrasound between the $11^{\text {th }}$ and $14^{\text {th }}$ week of amenorrhea. Ultrasound scans allow a general examination of the foetus and a nuchal translucency measurement, if the women so wish. Women then have another ultrasound between the $18^{\text {th }}$ and $20^{\text {th }}$ weeks. These two ultrasounds are performed by ultrasound technicians in the hospital in which the women have chosen to give birth. As a result of the longstanding medicalization of pregnancies, almost all women give birth in hospital (Oakley, 1993).

Uptake of DS screening in England was 61\% in 2010 (Ward, 2011a). The number of women having a diagnostic test was less than $2 \%$ in 2010 (Ward, 2011b).

\section{Screening policy in France}


Ultrasound and serum marker techniques were imported from the United Kingdom, but they became commonplace more rapidly in France (Vassy, 2006; Vassy, 2011). The obstetrical profession, so influential in the definition of policies governing care for pregnant women and infants, obtained funding for the tests from public authorities and the social security. The latter is a centralised funding organisation which sets the prices for certain medical consultations and tests, along with the level of reimbursement for the whole country.

Foetal ultrasound, which is carried out solely by doctors and midwives, came into general use in the middle of the 1980s when it became reimbursable. In 2010 there was an average of 5 scans per pregnancy (Blondel \& Kermarrec, 2011). The serum marker test also became more widely used in France when, after some hesitation, the government made it reimbursable in 1997. In return, it obliged practitioners to obtain signed informed consent forms from pregnant women. In 2010, $84 \%$ of women had serum-marker screening (Blondel \& Kermarrec, 2011).

In the 2000s, a number of legal decisions obliged healthcare professionals to pay high levels of compensation to parents with children whose foetal anomalies had not been detected. As a result, in 2005 the French national technical ultrasound committee, comprised of representatives of medical ultrasonographers, recommended that foetal neck measurements be taken on a systematic basis during the first-trimester ultrasound scan (Champenois-Rousseau and Vassy, 2012). But that same year, the French national health authority, which makes recommendations for quality of care, pointed out that whilst screening for DS should be systematically offered to pregnant women, it was not compulsory, unlike other pregnancy monitoring tests (HAS, 2005).

This confusion concerning professional standards goes hand in hand with pregnant women lacking knowledge of the tests. A non-negligible percentage believes the serum marker test 
and the measurement of nuchal translucency to be compulsory (Favre et al., 2007; Seror \& Ville, 2009). This screening has led to little public debate, despite criticism from the chairman of the national ethics advisory board, who in 2007 declared that it had become "virtually compulsory" (Sicard, 2007).

The large number of ultrasound and serum marker tests for DS led to an increase in the number of diagnostic tests offered to women if their risk is greater than $1 / 250$. In $2010,7 \%$ of women who had given birth had had one of these samples taken to diagnose DS (ABM, 2013). Where a diagnosis is confirmed, they can have a termination of pregnancy with no limit in time.

The increasing number of screening tests can also be explained by the dispersal of the healthcare professionals who monitor pregnant women. Pregnant women first contact a professional of their choice in private practice - obstetrician-gynaecologists, midwives or general practitioners who prescribe an ultrasound scan during the first trimester, which often includes measurement of nuchal translucency. They have this test with a private ultrasonographer. They are then managed by the hospital or clinic where they will be giving birth, the vast majority of births taking place in healthcare establishments, where they can be advised to have further ultrasound tests of better quality. At the time of our study, it was the healthcare professionals that they saw during the $4^{\text {th }}$ month of pregnancy - be they in private practice or at the hospital - who presented the serum marker screening (the combined firsttrimester screening not yet having been implemented).

This screening is part of a pregnancy-monitoring process which is already highly medicalised. Two thirds of pregnant women are monitored essentially by obstetrician-gynaecologists and $12 \%$ by midwives (Blondel \& Kermarrec, 2011). Pregnancy and birth are considered to be 
events presenting risks and are subject to a large number of medico-technical interventions (Akrich \& Pasveer, 1996; Carricaburu, 2005).

\section{Screening policy in the Netherlands}

In the Netherlands, the introduction of prenatal screening for DS, as with spina bifida before, caused major public controversies and reticence on the part of some political parties, policy makers and midwives (Katz-Rothman, 2001; Popkema \& Harbers, 2005; Stemerding \& Van Berkel, 2001). For several decades, public authorities restricted any large-scale implementation of prenatal screening, which was subject to experimentation by doctors in university hospitals. On several occasions, the Dutch parliament also expressed reticence on the subject. The arguments put forward by public authorities were of various natures: biomedical (the serum marker test was not sufficiently reliable), psychosocial (there was the risk of worrying women unnecessarily), ethical (the risk of eugenics), cultural (pregnancy is a natural event and not a medical one) and political (pregnancy is a private matter). In 2003, following various publications by the national health committee and pressure from obstetrician-gynaecologists, public authorities finally decided to provide a legislative framework for prenatal screening by integrating it into the Population Screening Act in 2007. The implementation of this programme is the responsibility of eight university hospitals, with which practitioners must enter into a contract both to receive training in counselling pregnant women and to refer them for tests. Restrictions also relate to abortion for foetal anomaly, this only being possible before the $24^{\text {th }}$ week of pregnancy.

Before 2007, prenatal screening and diagnosis were offered solely to women over 36 years of age and to those who showed a risk of foetal anomaly such as a family precedent. Women who were not in either of these categories had access to the tests if they made the explicit request during the consultation, but the cost was not reimbursed by the health insurance 
system. The practitioner was not allowed to take the initiative of informing women of the existence of these screening and diagnosis tests. Since the law came into force in 2007, practitioners have been obliged to systematically offer information on these tests during the first consultation, and to verify in advance that the woman concerned has no objection, in principle, to such information being offered. Finally, the test is still not free for women under 36 and not in the categories at risk - in 2009 the cost was 130 euros. Consultations are paid directly by the health insurance companies concerned.

Restrictions on screening are part of the tradition of low medicalization of pregnancies and births, which are considered to be natural events which take place, a priori, without medical intervention (Akrich \& Pasveer, 1996; Pasveer \& Akrich, 2001). Pregnancies are monitored by midwives, most of whom have private practices (Hingstman \& Kenens, 2010). Midwives detect whether or not a pregnancy is pathological and then refer pregnant women to a hospital obstetrician. Birth is not medicalised to any great extent: a quarter of children are born at home and another quarter on an out-patient basis in a hospital, without medical equipment, assisted by midwives, close to a technical unit should one be needed. Where there are no complications, the mother and child leave the hospital a few hours after the birth.

Routine monitoring consists in only two ultrasound scans: the dating ultrasound and, since 2006, a "structural" ultrasound which is performed between 18 and 22 weeks to monitor foetus development and detect any anomalies. Regarding prenatal screening for DS, midwives suggest the first trimester combined test. In 2009, $91 \%$ of pregnant women received information about prenatal screening but only $26 \%$ of them expressed the wish to have it (Fracheboud et al. 2011; Schielen, 2011). When the probability is higher than 1/200, women are offered a diagnostic test. According to our calculations, the percentage of live births to undergo foetal karyotyping in 2009 is approximately $4 \%$. 
Each of the three countries offers a specific profile, whether it be how the medical profession influences the definition of screening policy, the characteristics of policies and how pregnancy management is organised, or the number of tests carried out. Are these specificities reflected in the interactions between practitioners and pregnant women?

\section{Where and how the interaction takes place}

The first differences lie in where and how the interaction takes place. In England, the consultations we observed took place in community centres - public centres for families with young children - located in the districts where the women lived. The sole midwife consultation room is adjacent to the children's playroom and the social workers' offices. On the walls one finds activity timetables for children and parents and posters advertising services to help with addiction and over-indebtedness. The reception staff and the midwives are all in civilian clothing. Waiting time is short.

In France, the consultations we observed took place in a hospital's gynaecology-obstetrics department. All personnel wear white coats. Given the large number of people with appointments, one has to wait before being able to speak with someone at reception, then wait again before seeing a midwife or an obstetrician. The notice boards are used more to provide information to the personnel than to patients. This environment creates an asymmetrical relationship between the pregnant women and health practitioners.

In the Netherlands, the consultations observed took place in the private practices of midwives, located in the districts where the pregnant women live. The midwives are in civilian clothing and the waiting time is relatively short. In the waiting room there are games for children, magazines for young parents and information brochures on breastfeeding, pregnancy and practical local services. There are birth announcement cards on the walls. In the waiting 
rooms of two practices there was a book of photographs showing children with DS along with positive accounts by the parents. This book, The Upside of Down, by E. Snooijnk in partnership with the Upside of Down Foundation, was distributed free of charge to all Dutch midwifery practices in 2008 .

\section{Duration of the interaction and the number of clinical acts}

The duration of the consultation and what the practitioner must do during that time vary from one country to another. In England and in the Netherlands, the time scheduled in the diary for an initial consultation for pregnant women is one hour; in France it is thirty minutes. These times are determined locally - for example, in France, by the department's and hospital's directors; but they can also be influenced by national recommendations from professionals, as is the case in the Netherlands. This official theoretical time bears no relation to the actual duration that we observed. The average duration observed was 52 minutes in England, 40 minutes in France ( 31 minutes for doctors and 48 minutes for midwives) and 43 minutes in the Netherlands. The brevity of the official duration for consultations in France cannot be explained by a lesser number of tasks to be accomplished. In all three countries practitioners must fill in a form which includes questions on the medical history of the woman and her family, and of the future father and his family, their current state of health, details of their lifestyles (jobs, smoking, alcohol, drug addiction, etc.), details of any previous pregnancies, the woman's blood details, etc. Practitioners thus ask a large number of questions and give advice where necessary. In England, midwives must also take a blood sample and measure blood pressure. French practitioners do not do this, but they must read the examination results that the woman brings with her (for example, the ultrasound or blood results) and record them in the woman's file. In addition, they systematically perform a vaginal examination to check cervical closure, and possibly a smear test if the woman has not had one during the two 
previous years, to screen for cervical cancer. In the Netherlands, the midwives we observed performed no medical acts during the first consultation.

These time constraints lead to differences in the average time spent talking about screening, which stands at 4m49 in England, 3m09 in France (3m08 for midwives and 3m11 for doctors) and $6 \mathrm{~m} 35$ in the Netherlands.

\section{Timescales for information and decision-making}

Our studies show national specificities in screening timescales, i.e. the time between information being given to pregnant women and the moment at which they are asked to decide whether or not to have the test.

In England, pregnant women receive a 70-page national information brochure on all prenatal screenings available through the NHS, at the same time as a letter stating the time and date of the first appointment with the midwife. This brochure is also available on the NHS website. During the consultation, the midwives asked women whether or not they had read the brochure (which is not always the case) and went over the salient points with them. They asked them if they agreed to have the test, explaining that they needed an immediate answer to inform the hospital's ultrasound technicians, who would organise a lengthier appointment if the women wanted nuchal translucency to be measured. In most of the consultations the midwives told the pregnant women that if they asked for a screening they would be able to change their minds up until the following appointment with the ultrasonographer, as the latter would again ask for consent as a "double-confirm". Certain midwives apologised for having to ask for an immediate answer. But they are subject to two time constraints, that of making the ultrasound appointment and that of immediately ticking the boxes in the patient's file to show that they had provided information on the screening and whether or not the test had 
been accepted. Where there was a positive response, the midwives gave the women a form to take to the hospital for their screening.

In the French department we studied, pregnant women are given no information brochure, neither before nor during the consultation, and practitioners expect an immediate answer to the screening question. If the pregnant woman is in the appropriate gestational period and if she agrees to the screening, the practitioner can send her to have a blood sample taken within the department immediately after the consultation. This requirement to make an immediate decision is due to the time constraints inherent to the test, which must be done between the $15^{\text {th }}$ and $18^{\text {th }}$ weeks of amenorrhea, and which is suggested to women who are between the $11^{\text {th }}$ and $18^{\text {th }}$ weeks of amenorrhea. It is also due to the frequency of consultations, as the practitioner will not see the woman for another month. This time constraint is exacerbated by the use of two documents. Practitioners must state in the file whether or not they have informed the pregnant woman about screening, and whether or not they have prescribed it. They must use a national test consent form, which also serves as the prescription for the laboratory and must be signed by both the woman and the practitioner. If they have agreed to the test, most practitioners ask women to sign the form during the consultation, and they sign it without taking the time to read it. At the end of the consultation, women leave with a copy of the form, which they give to the nurse who takes the blood sample, so one might suppose that they read it later.

During consultations in the Netherlands, midwives give pregnant women a nationallyproduced 24-page brochure on screening for DS, which summarises the information given orally. The brochure can also be downloaded from the midwives' websites, which also provide a wide range of information on prenatal diagnosis. The women take the brochure away with them when they leave. They are not asked to make a decision during the 
consultation, but at a later date, unless they immediately express a clear opinion for or against screening. Midwives emphasise the fact that a hasty decision is not advisable and that the brochure should be shown to partners and discussed with them. They thus put the women in a state of reflection and at the end of the consultation, generally remind them to "think carefully", to "talk to their partners" and "not to make a too hasty decision". They can afford to adopt such an attitude, because women come to see them early on in their pregnancies, often between the $8^{\text {th }}$ and $10^{\text {th }}$ weeks. The written documents which are used do not add any time pressure. The midwives note down that they have informed the pregnant woman, not in the patient file but on a separate sheet of paper from the regional organisation in charge of prenatal screening, to which the sheet must be returned. On this same document they can also tick the woman's decision to have the test, if she has taken the decision immediately, or else return it unticked. If after thinking things through at home the woman decides to have the screening, she must return to the practice to obtain the forms needed to have the tests at the hospital.

So we can see three different organisational models relating to information and decisionmaking timescales. In England and the Netherlands, pregnant women have longer periods for reflection before or after the consultation and the presence of the brochure can encourage the woman to speak to the future father and maybe to friends or relatives, even though they do not attend the consultation.

\section{The optional nature of screening and respect for freedom of choice}

In England, during most of the consultations we observed, the midwives explicitly mentioned that screening was not obligatory and that the woman had to make a choice: "It's not a compulsory test, it's pure choice” or "you don't have to have this test". When they did not mention this optional characteristic at the start of the presentation, it appeared later on, when 
asking for consent: "Is that something you would want to have?" or "So, are you happy about that screening?" As we saw earlier, the midwives explained that consent would be requested once again at the hospital. We noted however that they tended to valorise the test, using expressions which put it across as a gift: "we offer you", perhaps to implicitly stress the fact that the screening is free of charge. Furthermore, during several consultations the midwife talked about the test in a laudatory manner, presenting it as being technically superior to those previously used, as a "gold standard test". These results confirm Pilnick's (2008). Finally, the midwives we observed said little about diagnostic examinations, which they referred to in the form of euphemisms: "you'll be offered further tests".

In most of the consultations we observed in France, the practitioners mentioned the optional nature of the test, either at the beginning of their presentation, or else at the end, while asking for consent. But they sometimes talked in a highly positive manner about the screening: "It's important to detect it (DS) because it's a very frequent disease”. We also observed flagrant deviations from the notion of informed consent. During two consultations the midwife did not mention the optional nature of the test. She asked what the woman knew about it or whether she remembered having had the test for a previous pregnancy, before moving on to a description of the test and to asking the woman to sign the consent form. Finally, in seven consultations the practitioners mentioned the optional nature of the screening but purposely oriented the woman's choice. In six of these cases they thus drew the women into accepting the test. In these consultations the women presented one or more of the following characteristics: being 38 years old or more, being of foreign origins, having financial problems or suffering from a chronic pathology. When faced with a woman from the Ivory Coast, HIV-positive and mother of three children with housing problems, one midwife answered her own questions: "Um ... if you had a Down's Syndrome problem, would you keep 
the baby or not? (The pregnant woman does not answer and makes a face). No, in any case, that's the problem ... so we'll do the test then? Okay." Another midwife states her own position: "It's not compulsory, you can refuse ... but it's strongly recommended".

In the Netherlands, the midwives we observed said that they offer not the test but information about the test. They tell women that they are "offering" them this information, using the verb "aanbieden" which has a positive connotation, but they always explain that the screening is not compulsory. "Nothing is compulsory, everything is possible". Sometimes they explain that they are obliged to give out information on the screening, and make allusions to the new legislative framework: "we are obliged to provide all pregnant women with information on tests". Some tell women that they may refuse to have information about the screening: "You are entitled to say: I don't want to know anything about it". When they talk about the choice to be made, the midwives' discourse contains several warnings. They draw attention to the consequences of a test showing a high-risk result and to the difficult decisions that must then be made: choosing whether or not to have an amniocentesis or trophoblast biopsy, which are risky because they can cause a miscarriage, and then maybe deciding whether to medically terminate the pregnancy if an anomaly is confirmed. Such notes for caution can also relate to how test results are interpreted: "Even if the (announced) probability is small, you might still give birth to a little Mongol baby". Finally, they remind patients under 36 years old that the test costs 130 euros and is not reimbursed. The midwives' discourse alternates between a biomedical register, where they provide information on risk calculation and on the probability of having a child with an anomaly, and a conversational register, which involves reassuring mothers-to-be by encouraging them "to think about having a healthy baby" and by trivialising the risk of having a "mongooltje" (little Mongol child), where the diminutive form mitigates the negative connotation and adds an affectionate dimension. 


\section{The decisions made by pregnant women}

The final specificity relates to the levels of acceptance for screening. In England, 12 women out of the 16 observed accepted to have the test, 2 refused and 2 hesitated and did not make a decision. In France, 31 consultations out of 34 ended with an agreement to have the screening. In the Netherlands, only 8 women out of 25 said they were interested in having the screening, 12 said they were not interested and the remainder hesitated. Although it is not possible to draw any conclusions from such small samples, it is interesting to note that the percentage of women we observed who accepted to have the test is not very different from national percentages.

\section{Discussion}

Analysis of the consultations shows several differences between countries: where and how the interaction takes place, its duration, the timescale in which the healthcare professional provides the information and during which the women make their decisions, and the type of information provided. These differences reflect national specificities in screening-policy characteristics and in the way that healthcare systems are organised.

In England, the screening policy is implemented by a centralised organisation, via a network of practitioners who coordinate its local application. Within this state-funded health system, all pregnant women must follow a unique healthcare path, which makes it easier to coordinate and train personnel.

In the consultations we observed, interaction was lengthy and took place in a context which did not create any position of inequality between the practitioner and the pregnant woman. Information was provided both before and during the consultations, but the imposing size of 
the brochure meant that the information was not easily accessible. Furthermore, women must give an immediate answer and professional discourse is sometimes in favour of screening. Women can however change their minds at a later date and thus have some room for manoeuvre.

In France, the screening policy is embedded in the tradition of medicalising pregnancy and of having a large number of tests paid for by the social security system. Healthcare practitioners, spread over the private and public sectors, have the responsibility of implementing screening, without being given any additional resources, but with the obligation to obtain a signed informed consent form from pregnant women.

The brevity of the consultations observed, the fact that information is provided only on the day of the consultation and the demand for an immediate answer combine with a professional discourse often in favour of screening to encourage women to have the test and even, in certain cases, to encourage the imposition of medical acts. When women do not wish to have the test, they must argue their wish to opt out.

In the Netherlands, for a long time public authorities refused to develop any screening policy and practitioners were not allowed to take the initiative to discuss it with patients who were not in a risk category. The current policy requires practitioners to be trained and to discuss screening with pregnant women, whilst at the same time respecting their right not to be informed. If a woman is under the age of 36 , she must pay for the tests herself.

The characteristics of the consultations we observed were often opposite those found in France: interaction is lengthy and takes place in a low-medicalised environment, and the information is provided both during and after the consultation. Decision-making is postponed to a later time, which obliges women to return to the practice to collect the required forms, 
and professional discourse encourages women to think about the consequences of the different choices. Although some people might qualify the cost of the test as an economic obstacle, others emphasise its beneficial effect in avoiding the imposition of medical techniques in relation to screening (Thornton, 1999). We believe the Dutch framework to be the one which is closest to an opt-in process, where women must take active steps to have screening.

\section{The limits of our study}

Our research is a qualitative study which does not target the representativeness of national practices. It should be completed by additional fieldwork to assess the consequences of infranational local variations on the interaction process. In France, our sample includes a high proportion of working class people and/or immigrants from West and North Africa. However, it is unlikely that this class status and/or ethnicity influences compliance with screening procedures because the number of women in our sample accepting the screening test is similar to the average French rate. Moreover, if these factors did have an impact, one would expect them to reduce the screening uptake rate. Research studies have shown that in many countries women in socially deprived groups and minority ethnic groups have a lower uptake of DS prenatal screening, even if opinions vary on the reasons for this (Dormandy et al., 2005; Fransen et al., 2010; Khoshnood et al., 2004; Sandall et al., 2003).

The scope of our research is also limited by the fact that we did not study exactly the same screening techniques in all three countries. In England and the Netherlands, we examined the implementation of combined screening through serum markers and ultrasound during the first trimester, and in France we looked at serum-marker screening during the $2^{\text {nd }}$ trimester. In France we were only able to study the technique which was the most frequently used at the time of our research. However the implementation of first-trimester combined screening in 
France since 2009 does not appear to have changed practices, with the national uptake rate remaining at $82 \%$ in 2011 ( $\mathrm{ABM}, 2013)$.

Finally, our study sets out the characteristics of public screening policies and offers certain sociohistorical elements to help understand their development. However, it is not an exhaustive analysis. Other social factors can affect the creation of public policy, such as the social representations of disability or the respective roles of the State and of the medical profession in public health.

\section{Conclusion}

The existence of national variations in test implementation shows that there is no technical determinism in prenatal screening. The characteristics of public policies and of the health systems in which they are implemented, influence the process of interaction between healthcare professionals and pregnant women, thus orienting their choice regarding prenatal screening. The script embedded in the English mechanism offers a slight encouragement to women to have the screening test; the French script expects them to accept it and the Dutch script makes tests available to them, without encouraging them to accept.

The scripts which we have identified might also help to explain the differences between the 3 countries regarding the rate of termination of pregnancy for foetal anomaly. The number of pregnancy terminations for foetal anomaly per 10,000 births in 2000-2005 is 4.8 in England, 9.5 in Paris (data for 2005 only) and 1.4 in the northern part of the Netherlands (Garne et al, 2010). This statistic ranks the three countries in the same order as our data. It is a global figure, which highlights the choice of pregnant women to terminate the pregnancy when a foetal anomaly is identified, but also the performance of the health service regarding the detection of foetal anomalies. 
Our analysis puts into perspective the ideology of a patient's freedom of choice. It follows other works which show that maternity care systems shape the desire of women for maternity care services (DeVries et al., 2001). Our study shows the importance of the choices made by those who define the public policies regarding biomedical innovation. In England and in the Netherlands, steps have been taken to preserve the exceptionality of screening (information, training, payment, etc.); this is not the case in France.

Our analysis also shows the limits of political choices, which are constrained by the existence of specificities in healthcare systems. The previous medicalization of pregnancy in France and the dispersal of practitioners would appear to make it harder to develop a public policy to control how innovations are used, which unintentionally leads to almost systematic screening.

Moreover there is no one-way relationship between public policy choices and practices in consultations, the former determining the latter. The reverse relationship also exists. In the 3 countries, biomedical innovations were used by practitioners and pregnant women, before being subject to formal regulations. In France, the high uptake rate of screening, which reflects practices, is presented as a sign that the current policy is well-suited to public needs, and helps to silence critics.

Other studies are needed to see if there are any regularities in the way in which public authorities integrate biomedical innovations into healthcare systems. The upcoming introduction of a new test, described as non-invasive, which will be able to detect various trisomies, and then other genetic pathologies through analysis of the foetal genome using a single maternal blood sample at the start of pregnancy, will force governments to take on new responsibilities in relation to the availability and regulation of innovations. 


\section{Bibliography:}

ABM (2013). Rapport médical et scientifique de l'assistance médicale à la procréation et de la génétique humaine en France. Agence de la Biomédecine

Akrich, M. (1992). The De-Scription of Technical Objects. In W. Bijker \& J. Law, Shaping Technology, Building Society (pp.205-224). Cambridge: MIT Press.

Akrich, M. \& Pasveer, B. (1996). Comment la naissance vient aux femmes. Les techniques de l'accouchement en France et aux Pays-Bas. Le Plessis-Robinson: Synthélabo.

Alaszewski, A., \& Brown, P. (2012). Making health policy. Cambridge: Polity Press.

Armstrong, N, \& Eborall, H. (2012). The sociology of medical screening: past, present and future. Sociology of Health and Illness, 34, 161-176.

Asch, A. (1999). Prenatal diagnosis and selective abortion: a challenge to practice and policy. American Journal of Public Health, 89, 1649-1657.

Baszanger, I., Gaudillière, J.P., \& Löwy, I. (2000). Avant-Propos. Sciences sociales et santé, $18,5-8$.

Benamouzig, D. (2010). Système de santé. In D. Fassin \& B. Hauray, Santé publique : l'état des savoirs (pp.317-328). Paris: La Découverte.

Blondel, B. \& Kermarrec, M. (2011). Enquête nationale périnatale. Les naissances en 2010 et leur évolution depuis 2003. Rapport Inserm.

Carricaburu, D. (2005). De la gestion technique du risque à celle du travail : l'accouchement en hôpital public. Sociologie du Travail, 47, 245-262. 
Champenois-Rousseau, B., \& Vassy, C. (2012). Les échographistes face au dépistage prénatal de la trisomie 21 . Le difficile arbitrage entre excellence professionnelle et éthique du consentement, Sciences sociales et santé, 30, 4, 39-63.

Crombag, N., Bensing J., Iedema-Kuper R., Schielen, P., \& Visser G. (2013). Determinants affecting pregnant women's utilization of prenatal screening for Down syndrome: a review of the literature. Journal of Maternal-Fetal \& Neonatal Medicine, 26, 1676-1681.

DeVries, R., Salvesen H., Wiegers T., \& Williams A. (2001). What (and why) do women want? The desire of women and the design of maternity care, in R. De Vries, C. Benoit, E. van Teijlingen, \& S. Wrede (Eds.), Birth by design: Pregnancy, maternity care, and midwifery in North America and Europe (pp. 243-266). New York: Routledge.

Dormandy E., Michie S., Hooper R. \& Marteau Th. (2005). Low uptake of prenatal screening for Down syndrome in minority ethnic groups and socially deprived groups: a reflection of women's attitudes or a failure to facilitate informed choices? International Journal of Epidemiology, 34, 346-352.

Faulkner, A. (2012). Resisting the screening imperative: patienthood, populations and politics in prostate cancer detection technologies for the UK. Sociology of Health and Illness, 34, 221233.

Favre R. et al. (2007). How important is consent in maternal serum screening for Down syndrome in France? Prenatal Diagnosis, 27, 197-205.

Fracheboud, J., van Agt, H., \& de Koning, M. (2011). Monitoring 2009. Screeningsprogramma Downsyndroom, Structureel Echoscopisch Onderzoek, Rotterdam: Erasmus MC. 
Fransen, M.P., Schoonen M. H., Mackenbach J. P. et al. (2010). Ethnic differences in participation in prenatal screening for Down syndrome: A register-based study. Prenatal Diagnosis, 30, 988-994.

Garne, E., Khoshnood, B., Loane, M., Boyd, P., \& Dolk, H. (2010). Termination of pregnancy for fetal anomaly after 23 weeks of gestation: a European register-based study, British Journal of Obstetrics and Gynaecology, 117, 660-666.

Green, J.M., \& Statham, H. (1996). Psychosocial aspects of prenatal screening and diagnosis. In Th. Marteau \& M. Richards, The troubled helix (pp.140-163). Cambridge: Cambridge University Press.

Griffiths L. (2003). Making connections: studies of the social organisation of healthcare, Sociology of Health \& Illness, 25, 155-71.

Hantrais, L., \& Mangen, S. (1996). Cross National Research Methods. London: Pinter.

HAS (2005). Comment mieux informer les femmes enceintes. Saint-Denis: Haute Autorité de Santé.

Hingstman, L., \& Kenens, R. (2010). Cijfers uit de registratie van verloskundigen. Peiling 2010, Utrecht: NIVEL Report.

Katz-Rothman, B. (2001). Spoiling the pregnancy: Prenatal diagnosis in the Netherlands. In R. De Vries, C. Benoit, E. van Teijlingen, \& S. Wrede (Eds.), Birth by design: Pregnancy, maternity care, and midwifery in North America and Europe (pp. 180-198). New York: Routledge.

Kerr, A. (2004). Genetics and Society, London: Routledge.

Khoshnood, B., Blondel, B., De Vigan, C., \& Bréart, G. (2004). Socioeconomic barriers to informed decision-making regarding maternal serum screening for Down Syndrome: Results 
of the French national perinatal survey of 1998. American Journal of Public Health, 94, 484491.

Marteau, Th., Slack, J., Kidd, J., \& Shaw, R. (1992). Presenting a routine screening test in antenatal care: practice observed. Public Health, 106, 131-141.

NICE (2003). Antenatal care: routine care for the healthy pregnant woman. National Institute for Clinical Excellence.

NSC (2008). NHS Fetal Anomaly Screening Programme - Screening for Down's syndrome: UK National Screening Committee Policy Recommendations 2007-2010.

Oakley, A. (1993). Essays on Women, Medicine and Health. Edinburgh: Edinburgh University Press.

Pasveer, B. \& Akrich, M. (2001). Obstetrical trajectories: on training women/bodies for (home) birth, In R. De Vries, C. Benoit, E. van Teijlingen, \& S. Wrede (Eds.), Birth by design: Pregnancy, maternity care, and midwifery in North America and Europe, (pp.229242). New York: Routledge.

Petrogiannis, K., Tymstra, T., Jallinoja, P., \& Ettore, E. (2001). Review of policy, law and ethics. In Ettore E. (Ed.), Before birth. Understanding prenatal screening (pp.38-52). Aldershot: Ashgate.

Pilnick, A., (2008). It's something for you both to think about': choice and decision making in nuchal translucency screening for Down's syndrome. Sociology of Health and Illness, 30, $511-530$.

Popkema, M. \& Harbers, H. (2005). The cultural politics of prenatal screening, in H. Harbers (Ed.) Inside the politics of technology. Agency and normativity in the co-production of technology and society (pp.229-256). Amsterdam: Amsterdam University Press. 
Press, N., \& Browner, C. H. (1997). Why women say yes to prenatal diagnosis. Social Science \& Medicine, 45, 979-989.

Rapp, R. (2000). Testing Women, Testing the Fetus. New York: Routledge

Reid, B., Sinclair, M., Barr O., Dobbs, F., \& Crealey, G. (2009). A meta-synthesis of pregnant women's decision-making processes with regard to antenatal screening for Down Syndrome, Social Science and Medicine, 69, 1561-1573.

Reid, M. (1991). The diffusion of four prenatal screening tests across Europe. London: King's Fund Centre.

Sandall, J., Grellier, R., \& Ahmed, S. (2003). Prenatal screening and diagnosis in a multicultural, multi-ethnic society. In L. Abramsky \& J. Chapple, Prenatal diagnosis. The human side (pp.83-97). London: Chapman and Hall.

Seror, V. \& Ville, Y. (2009). Prenatal screening for Down syndrome: women's involvement in decision-making and their attitudes to screening, Prenatal Diagnosis, 29, 120-128.

Sicard, D. (2007). La France au risque de l'eugénisme, Le Monde, 4 février.

Schielen, P. C. (2011). Quality control parameters of the Dutch Down syndrome screening Laboratories 2009. Utrecht: National Institute for Public Health and the Environment.

Schwennesen, N., Svendsen, M., \& Koch, L. (2010). Beyond informed choice: prenatal risk assessment, decision-making and trust. Clinical Ethics, 5, 207-216.

Stemerding, D., \& Van Berkel, D. (2001). Maternal serum screening, political decisionmaking and social learning. Health Policy, 56, 111-125. 
Thornton, J. (1999). Should health screening be private? London: IEA Health \& Welfare Unit.

Tsouroufli, M. (2011). Routinisation and constraints on informed choice in a one-stop clinic offering first trimester chromosomal antenatal screening for Down's syndrome. Midwifery, 27, 431-436.

Vassy, C. (2006). From a genetic innovation to mass health programmes: the diffusion of Down's Syndrome prenatal screening and diagnostic techniques in France, Social Science and Medicine, 8, 2041-2051.

Vassy, C. (2011). De l'innovation biomédicale à la pratique de masse : le dépistage prénatal de la trisomie 21 en Angleterre et en France, Sciences Sociales et Santé, 29, 3, 5-32.

Ward, P. (2011a). Down's syndrome screening in England, NHS Fetal Anomaly Screening Programme; Committee UNS.

Ward, P. (2011b). FASP Progress Update, NHS Screening Programmes, Fetal Anomaly, Spring.

Williams, Cl., Alderson, P., \& Farsides, B. (2002). Is non-directiveness possible within the context of antenatal screening and testing? Social Science \& Medicine, 54, 17- 25. 